\title{
NOS TRILHOS DE UMA URBANIDADE EXCLUDENTE: PRODUÇÃO DO ESPAÇO EM UBERLÂNDIA/MG ${ }^{1}$
}

\section{In The Rails of A Urbanity Exclusive: The Official Building of Uberlândia City}

\author{
Flávia Gabriella Franco Mariano \\ Mestranda em Ciências Sociais - Universidade Federal de Uberlândia \\ flavia_dmc@homail.com
}

\section{Resumo}

Este artigo busca percorrer os caminhos sob os quais trilharam a formação e o desenvolvimento urbano da cidade de Uberlândia desde os primórdios da elevação à categoria de cidade a antiga vila São Pedro de Uberabinha. Tivemos como objetivo geral analisar a formação e a organização estrutural da cidade identificando discursos e sentidos que permeiam os espaços urbanos e atentando-nos a compreender o teor ideológico e estratégico na formulação da urbanidade. Discutimos como a adequação da forma urbana às mudanças e necessidades econômicas assentaram-se em uma história oficializada por meio de símbolos da ordem, do progresso e da modernização, delineando configurações sociais e espaciais de uma cidade excludente.

\section{Palavras-chave}

Cidade, Segregação urbana, Uberlândia

\section{Abstract}

This article seeks to walk the paths trodden under which the formation and spatial development of the city of Uberlândia since the elevation to city the ancient village of San Pedro Uberabinha. We aim to analyze the formation and structural organization of the city identifying discourses and senses that underlie urban spaces and paying attention us understand the ideological and strategic content in the formulation of the urbanity. We think about how the adequacy of urban form changes for the economic needs, were based on a story by official symbols of order, progress and modernization, outlining social and spatial configurations of a exclusive city.

\section{Keywords}

City, Urban segregation, Uberlândia

\footnotetext{
${ }^{1}$ Este texto é parte da monografia intitulada "QUANDO MORAR É PRIVILÉGIO: ocupação do espaço urbano e as lutas populares por moradia em Uberlândia/MG".
} 
Em 1895 era inaugurada em São Pedro de Uberabinha a Estação da Companhia Mogiana de Estradas de Ferro e Navegação². A chegada da Mogiana representava a materialidade da ufania e das inspirações de progresso e modernidade que caracterizaram a origem e a trajetória histórica da cidade de Uberlândia.

Ainda que o projeto inicial da Companhia, de levar a Mogiana até Goiás, não tenha se realizado sequer em ultrapassar a cidade vizinha Araguari, sem dúvida este acontecimento tem notoriedade na historiografia local à medida que se fixou como uma das mais importantes expressões materiais do projeto político hegemônico na cidade de Uberabinha em fins do século XIX, o qual determinaria sua estruturação e organização territorial no período seguinte.

Conforme aponta a historiadora Sandra Mara Dantas, a cidade de Uberlândia

[...] assenta-se em um imaginário bastante ufânico. Desde os primeiros anos de sua emancipação político-administrativa, em 1888, Uberlândia arvora-se destinada ao progresso. E a fim de concretizar tal ideal, foi forjado, na primeira metade do século $\mathrm{XX}$, um discurso que buscou imprimir à cidade uma imagem de ordem e progresso, civilidade e modernidade (DANTAS, 2001, p.4)

A instalação da Estação da Mogiana engrandecia as aspirações de consolidar a cidade como referência regional. A relevância política da ligação a outros centros urbanos e comerciais de São Paulo e Minas Gerais marca com relevância os vestígios históricos que registram a euforia criada sob o simbolismo daqueles trilhos. Resguardava implicitamente, entretanto, a construção e a naturalização de um imaginário que emergia da intencionalidade e da instrumentação de uma classe dirigente econômica e politicamente.

\footnotetext{
${ }^{2} \mathrm{~A}$ Companhia Mogiana de Estradas de Ferro e Navegação havia sido fundada através da Lei Provincial no14 em 1872 por fazendeiros de Campinas, com plano inicial de se estender até a região de Ribeirão Preto, que se destacava pela produção de café. Na década de 1880, a direção da Mogiana assinou contrato com o governo de Minas Gerais para estender um ramal sob o Rio Grande, distante $60 \mathrm{Km}$ do município de Uberaba. Nos anos seguintes, já na República, a Mogiana manteve sua expansão no Triângulo Mineiro, criando novo projeto, o Ramal Catalão, que levaria a estrada até Goiás passando pela cidade de Uberabinha (LOURENÇO, 2010).

URBANA, V.6, no 9, ago-dez, 2014 - Dossiê: Dimensões Simbólicas das Intervenções Urbanas CIEC/UNICAMP
} 
As transformações que se iniciaram a partir da Mogiana delineavam um processo de transição que extravasava a Lei no 23 de 24 de maio de $1892^{3}$, que elevava à categoria cidade a antiga vila São Pedro de Uberabinha. O espaço urbano seria reestruturado projetando um determinado modelo de cidade moderna a ser construída.

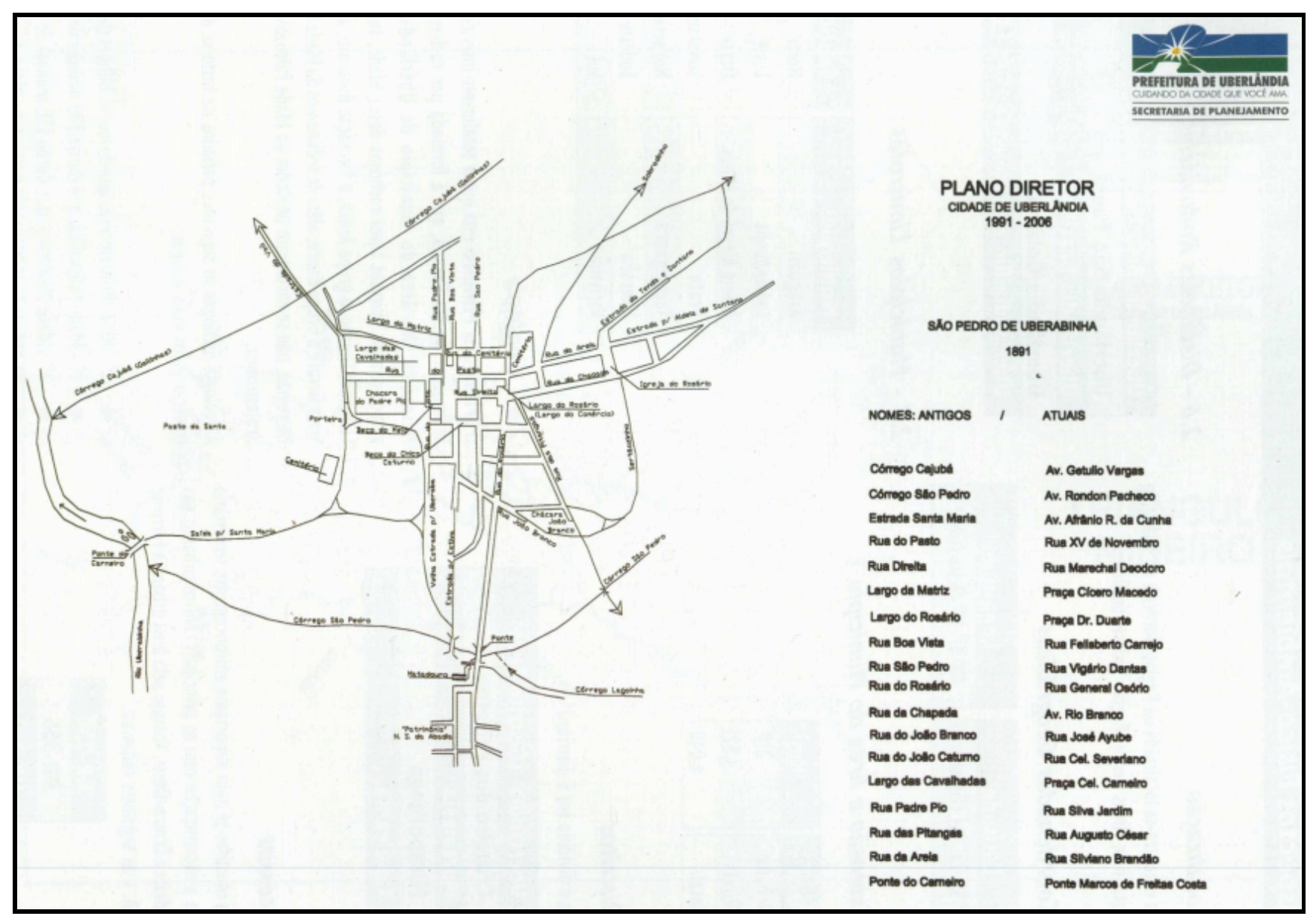

Figura 1 - Mapa de São Pedro de Uberabinha (1891)

Fonte: Prefeitura Municipal de Uberlândia

Conforme afirma Valéria Maria Queiroz Cavalcanti Lopes (2008), Uberlândia possui uma história oficializada, desde a origem, por meio de símbolos da ordem, do progresso e da modernização. A construção simbólica em torno destes valores ideais teria assentado o esforço das elites dirigentes para organizar uma rede de convivências, na qual os interesses emergentes foram tramados para possibilitar a materialização e a oficialização destes discursos no espaço urbano.

\footnotetext{
${ }^{3}$ A lei no 23 de 24 de maio de 1892 elevou à categoria de cidade todas as vilas, sedes de comarca da província (DANTAS, 2001).

URBANA, V.6, no 9, ago-dez, 2014 - Dossiê: Dimensões Simbólicas das Intervenções Urbanas CIEC/UNICAMP
} 
Podemos afirmar que a adequação da forma urbana às mudanças e necessidades de acumulação do capital produziu transformações que aliaram a funcionalidade técnica voltada ao lucro ao caráter simbólico de transpor monumentalmente para o urbanismo a exaltação do próprio sistema que se expandia, em conformidade com a observação de Joseph Rykwert:

Construir não é apenas uma questão de "função + estética", mas exige ser pensado em certa medida como uma representação (e, portanto, também como comentário) sobre os costumes da sociedade. Afinal, não se trata de um objeto isolado e sim como algo inscrito em um contexto físico o que exige avaliar a implicação metafórica [...] (RYKWERT, 2004, p. 374-377)

A ideia de "ordem e progresso", que abarcou desde a ação política institucional para propiciar o desenvolvimento econômico até o "planejamento e a disciplinarização do seu espaço urbano, aliando o gosto estético à ordem" (MACHADO, 1991, p. 38), foi impressa na urbanidade, nas formas de apropriação e uso da terra urbana e nas condições de vida da população da cidade.

Este projeto de renovação e mudanças políticas, econômicas, culturais e concretas, todavia, não havia sido inaugurado em São Pedro de Uberabinha. Bem como indica Ermínia Maricato (1997), a urbanidade das cidades brasileiras marca-se por uma conjunção de acontecimentos que influenciaram fundamentalmente a ampliação e a formação dos espaços urbanos no país a partir do fim do século XIX.

O fim da escravidão que havia feito com que milhares de trabalhadores escravizados fossem expulsos do campo e migrassem para a cidade, a chegada dos imigrantes europeus ao Brasil para trabalhar no campo e também a nascente indústria brasileira são fatores que confluíram para um movimento de crescimento e reestruturação das cidades brasileiras (MARICATO, 1997). Não menos importante, acrescenta-se a então recente substituição da monarquia pelo regime republicano para o desenho de um cenário de rupturas e projeções. A conjuntura do país na última década do século XIX apresentava elementos políticos, econômicos e culturais suficientes para a produção de um ensejo nacional por renovação social com a tônica do progresso através da modernização.

Inseridas neste processo, não somente na região mineira as cidades iniciaram projetos modernizadores na busca por notoriedade, reestruturando o espaço urbano sob um novo modelo de cidade. Tais condições conjunturais, além de provocar o aumento da extensão e da população das cidades, acarretaram também transformações em suas demandas (MARICATO, 1997). O período que abrange a URBANA, V.6, no 9, ago-dez, 2014 - Dossiê: Dimensões Simbólicas das Intervenções Urbanas CIEC/UNICAMP 
emergência do século XX reconfigura a vida urbana, propondo a reconstrução das cidades condizente com o projeto moderno, conforme discorre Edward Relph:

Os princípios que norteavam esses projetos tinham como pressupostos os preceitos de beleza, ordem e limpeza. As áreas urbanas deveriam, portanto, concretizar o pensamento daquela época, no qual o desenvolvimento econômico impunha um ordenamento do espaço em nível técnico, em que seriam privilegiados o transporte urbano, programas de saneamento para a construção de redes de esgoto sanitário e outros equipamentos necessários à vida urbana, fazendo com que as cidades fossem limpas e belas, registrando o progresso da sociedade moderna (RELPH, 1990, p. 47).

Esta ideia de planejamento urbano linear aliava-se a afirmação de um discurso universalizante que, sobretudo em diversos países da América Latina, "incorporou o Estado como a figura central para assegurar o equilíbrio econômico e social, e um mercado de massas" (MARICATO, 2000, p. 126). As cidades precisavam estar preparadas para suas novas funções e demandas e, mais que isso, renovar-se incorporando a forma urbana à simbologia da modernidade. Até pelo menos meados de 1940, é possível averiguar no Brasil reestruturações urbanas significativas baseadas em uma noção de melhoramento e embelezamento das cidades.

O discurso oficial, que buscava enaltecer as potencialidades de desenvolvimento e de destaque regional do que viria a ser Uberlândia elaborou um ideário de orgulho e projeção futurista com evidente impacto na cultura e nas vivencias locais. A adequação aos padrões que caracterizariam a modernização, expressos na síntese da ideia do progresso, porém, exigia também a reformulação espacial, estabelecendo, pela primeira vez, a ação oficial de planejamento urbano.

Sob esta perspectiva é que foi elaborado, na primeira década do século $\mathrm{XX}$, o primeiro projeto urbanístico da cidade de Uberabinha, postulando a construção de largas avenidas arborizadas e a demarcação de uma área central (SOARES, 1995). Esta configuração de cidade provocou, desde o início, uma divisão absoluta na apropriação da terra urbana, fragmentando áreas específicas para as atividades de comércio, lazer e residência com diferenciações entre ricos e pobres.

A partir da instalação dessa nova estrutura urbana, os empresários passam a investir em imóveis comerciais nas avenidas Afonso Pena e Floriano Peixoto; e na construção de belas e luxuosas residências, nas avenidas Cipriano Del Fávero e João Pinheiro. Essas avenidas rapidamente receberam serviços públicos básicos, tais como redes de distribuição de água e de coleta de esgoto sanitário, arborização, iluminação pública e calçamento, para que

URBANA, V.6, no 9, ago-dez, 2014 - Dossiê: Dimensões Simbólicas das Intervenções Urbanas CIEC/UNICAMP 
pudessem ser ocupadas, principalmente, por prédios comerciais e de serviços e residências de luxo (SOARES, 1995, p. 107).

O conteúdo e a forma destas mudanças podem ser compreendidos como expressão e fundamentação da substancial expansão das relações capitalistas e de suas bases materiais na região. Ocorre que a construção da cidade, bem como sua estruturação física, não acontece por acaso, mas de maneira pensada e arquitetada pelas múltiplas experiências que abriga e, não menos, para que convirja com as necessidades socioeconômicas do modelo dominante.

$\mathrm{Na}$ primeira década do século $\mathrm{XX}$, pois, Uberabinha já registrava 0 terceiro maior índice de importação através da Estrada de Ferro Mogiana, depois de Uberaba e Araguari (BOSI, 2004). Mais que números, os índices de transportação da Mogiana a partir destas cidades significava seu desponte como centros comerciais da região, explicitando fundamentalmente a lógica da racionalidade mercantil no projeto de desenvolvimento local.

Faz sentido, ainda, o apontamento do historiador Antônio de Pádua Bosi (2004), que considera como condição para o desponte de Uberabinha a construção da via intermunicipal, que permitiria a ligação do Triângulo Mineiro ao sul de Goiás, conectando a cidade à recém-construída ponte Afonso Pena, sobre o Rio Paranaíba. Em 1913 concluía-se a obra que iniciaria o desenvolvimento de uma malha rodoviária que, conforme aponta Bosi (2004), possibilitou que Uberabinha assumisse papel de entreposto comercial na divisão do trabalho inter-regional.

O engate da formação econômica da cidade se constituiu na extensão dos trilhos por suas terras, mas a integração com a economia paulista e de outros estados por meio da tríade ferrovia-rodovia-ponte Afonso Pena vieram a solidificar seu domínio regional, bem como observa o economista Eduardo Nunes Guimarães (2010). A criação da Companhia Mineira de Auto Viação Intermunicipal em 1912, por iniciativa privada, e o início da malha rodoviária possibilitou ao capital comercial sediado em Uberlândia apropriar-se de grande parte do excedente produzido em toda a região (GUIMARÃES, 2010).

Assim, a paisagem urbana manteve-se em transformação conjuntamente com o desenvolvimento econômico, buscando substituir a imagem da velha Uberabinha de tortuosas e estreitas de ruas onde circulavam carroças, pelo vislumbre de uma nova cidade, das modernas edificações padronizadas e das extensas vias simétricas por onde trilhariam mais que pessoas e mercadorias, mas novos sujeitos e símbolos urbanos.

URBANA, V.6, no 9, ago-dez, 2014 - Dossiê: Dimensões Simbólicas das Intervenções Urbanas CIEC/UNICAMP 
Para Pechamn (1993, p. 78), "a identificação da dualidade atrasado x moderno serve, portanto, de base para a criação de uma nova concepção de sociedade e para uma nova visão de cidade, numa economia que transita para o capitalismo". As transformações concretas que renovariam a cidade visaram, pois, fortalecer a impulsão de novos valores, atitudes e comportamentos que constituiriam uma nova noção de urbanidade.

A partir deste período teve início um amplo processo de reforma urbana com claro intuito de reorganizar a cidade segundo os interesses econômicos associados às atividades comerciais de cunho atacadista (BOSI, 2004). As dimensões socioespaciais redesenhavam-se reproduzindo as perspectivas políticas e econômicas das elites dirigentes, projetando um espaço urbano claramente segregado.

Percebe-se na formação urbana de Uberlândia um processo de produção de lugares desiguais, porém, ordenados para tal. As conjunções sociais, políticas e econômicas que condicionaram diferentes formas de apropriação do solo urbano revelam as constantes tensões entre o antigo e o novo e, sobretudo, entre interesses conflitantes.

À medida que a cidade se expandiu na primeira metade do século $X X$, estabeleceu-se o principal setor de comércio varejista, serviços e lazer nas avenidas Afonso Pena e Floriano Peixoto, alinhadas às proximidades das importantes praças Antônio Carlos e da Estação Mogiana ${ }^{4}$. Na mesma região, nas avenidas João Pinheiro e Cipriano Del Fávero, estabeleceram-se também o principal setor habitacional ocupado pelas elites econômicas e políticas da cidade. As antigas residências existentes nas áreas centrais foram aos poucos demolidas para abrir espaço para as casas comerciais e edifícios, conforme afirma Beatriz Ribeiro Soares (1995), expulsando a população de renda mais baixa, alojada em partes daquela área já há algum tempo.

Os preceitos estéticos que haviam banhado a cidade e os pressupostos de higienização do espaço urbano incluíam a eliminação das velhas e simplórias construções que, bem como seus moradores, não condiziam com o embelezamento almejado. Era necessário restringir a ocupação do espaço central às elites e o oferecimento de serviços urbanos, secundarizando a urbanidade das áreas do entorno. Estas características eram parte integrante do projeto de cidade.

Para Henri Lefebvre (2001) a cidade moderna pressupõe centralidades e a existência de um centro dinâmico repleto de urbanidade e espaços públicos. Entretanto, o autor identifica intrínseco ao urbanismo moderno o teor ideológico e

\footnotetext{
${ }^{4}$ Atuais Praça Clarimundo Carneiro e Praça Sérgio Pacheco, localizadas no Bairro Centro de Uberlândia. URBANA, V.6, no 9, ago-dez, 2014 - Dossiê: Dimensões Simbólicas das Intervenções Urbanas CIEC/UNICAMP
} 
estratégico da classe dominante na centralização dos acessos. Calcada sob uma racionalidade fragmentadora, o modelo de urbanidade moderna abarca a intensificação das segregações através da separação funcional das atividades e da sociedade no espaço (LEFEBVRE, 2001).

A partir do caso de Paris, Lefebvre (2001) descreveu o processo de expulsão dos trabalhadores do centro da cidade, reestruturando-a sob a imagem da nova classe dominante, que se remodelava sob os ventos da modernização. Da mesma forma, a exclusão e a concentração de renda marcaram decisivamente o processo de urbanização das cidades brasileiras.

Até a década de 1940 apenas $31 \%$ da população brasileira vivenciava condições urbanas, sendo as cidades símbolo da passagem moderna que avançaria sob o velho país agrário (MARICATO, 2003). A concentração fundiária é percebida como questão central em grande parte dos conflitos vivenciados no Brasil do século XIX, focados fundamentalmente no campo. A regulamentação do trabalho urbano, o incentivo à industrialização e a construção da infraestrutura industrial, dentre outras medidas, fortaleceram o aumento da migração do campo para as cidades e o desenvolvimento urbano do país no século $X X$, entretanto, sem superar algumas características dos períodos colonial e imperial, marcados pela concentração de terra, renda e poder.

A industrialização que tem início a partir da década de 1930 até os anos 50 constituiu um caminho de avanço relativo de iniciativas nacionais e de fortalecimento do mercado interno, com desenvolvimento de forças produtivas, diversificação, assalariamento crescente e modernização da sociedade (PRADO JÚNIOR, 1990). Os discursos ideológicos que permearam esta nova realidade impulsionaram, nesse sentido, a reestruturação dos espaços urbanos e dos modos de vida das populações urbanas de modo a sustentar o sistema urbano desigual entre classes sociais.

À medida que a efetividade da estrutura urbana não acompanhava o crescimento populacional, já na década de 1920 era possível identificar a relevância do déficit habitacional que atingiu significativamente a população trabalhadora de São Pedro de Uberabinha:

[...] a classe que não é dirigente e que vive do seu trabalho quotidiano, está sem lar, não têm habitação. É necessário que este problema não seja adiado e que o tratemos com respeito, como deve merecer a sorte desta gente que faz a prosperidade do país, desde o seu mais recondito distrito ao mais grandioso centro econômico. Aos poderes públicos municipais, aos capitalistas e construtores desta cidade compete a resolução do problema que já está URBANA, V.6, no 9, ago-dez, 2014 - Dossiê: Dimensões Simbólicas das Intervenções Urbanas CIEC/UNICAMP 
retardando a marcha de nossa vida expressiva pelo afastamento daqueles que, não podendo adquirir pelo preço exorbitante da habitação fogem de Uberabinha e estabelecem além, privando-nos do concurso de seus braços laboriosos, como a alimentação do povo, a sua habitação deve merecer o mesmo cuidado ${ }^{5}$.

Posto isso, a construção de casas a serem alugadas pelos operários passou a ser prática da companhia Mogiana e da Fábrica de Tecidos" ${ }^{6}$, pois "do ponto de vista deles, serviam para proteger suas empresas, além de fixar a mão de obra especializada, escassa na cidade" (SOARES, 1988, p. 32). O surgimento de outros loteamentos específicos para trabalhadores acompanhou o crescimento inicial da cidade. Estas vilas e as construídas pelo poder público municipal constituíram os primeiros subúrbios da cidade e evidenciavam a precariedade das condições de moradia dos trabalhadores e sua segregação inicial às áreas periféricas.

Pelo menos a partir do início das atividades industriais em Uberabinha neste período, os trabalhadores foram relegados a áreas longe dos locais de trabalho e do centro comercial, sem as mesmas condições de infraestrutura urbana. A observação deste processo permite evidenciar o caráter da organização inicial estabelecida na cidade, bem como analisa Milton Santos:

[...] um primeiro momento do processo especulativo vem com a extensão da cidade e a implantação diferencial dos serviços coletivos. O capitalismo monopolista agrava a diferenciação quanto à doação de recursos, uma vez que parcelas cada vez maiores da receita pública se dirigem à cidade econômica em detrimento da cidade social. Santos (1993, p. 96, grifo do autor)

Em 1940 a cidade contava com 7.000 lotes para uma população de 21.077 habitantes; em 1958 este número alcançava 28.271 lotes para uma população de 61.142 habitantes e, considerando-se cinco pessoas por lote, a cidade apresentava naquele momento um excedente de 16.043 lotes, ou seja, 56,5\% dos terrenos estavam desocupados (UBERLÂNDIA, 2009a).

Em meados da década de 50, Uberlândia abrigava 57.000 habitantes e apresentava significativos sinais de expansão no urbano (UBERLÂNDIA, 2009a). Para Beatriz Ribeiro Soares (1995) a criação da Cidade Industrial a partir da década de

\footnotetext{
${ }^{5}$ Jornal a Tribuna, 22 fev. 1925, apud SOARES, 1988.

6 Para Soares (1988) a construção de uma Fábrica de Tecidos em Uberlândia em meados da década de 20 foi a principal responsável por fazer com que "muitas famílias passassem a morar em suas proximidades, originando um bairro, denominado Vila Operária, que, em 1930, não tinha água, esgoto e luz elétrica" (SOARES, 1988: 32).

URBANA, V.6, no 9, ago-dez, 2014 - Dossiê: Dimensões Simbólicas das Intervenções Urbanas CIEC/UNICAMP
} 
1950 e seus desdobramentos talvez tenham sido o maior projeto político das elites uberlandenses, uma vez que, no início dos anos 60, essa cidade ainda era um núcleo urbano de pouca expressão no contexto mineiro.

É neste período que tem início outro importante projeto político pensado pelas elites locais e que viria a fortalecer a transformação da cidade e de sua urbanidade em referências regionais. O clima de progresso produziu também aspirações de que a cidade geograficamente bem situada, que desenvolvia a indústria e o comércio a passos largos, deveria também se caracterizar pelo aperfeiçoamento da cultura e do ensino superior. O processo que se estabeleceu desde a criação das primeiras Faculdades e da Cidade Universitária da Universidade de Uberlândia (UnU) nas décadas de 50 e 60 até a transformação desta em Universidade Federal de Uberlândia (UFU) em 1978 foi também tramado entre as elites políticas locais e nacionais em acordo com os interesses ascensão política e econômica da cidade.

Na década de 1950 o projeto de desenvolvimento modernista encampado pelo Brasil, e que permeou a construção de Brasília ${ }^{7}$, não escapou a encorpar os projetos em desenvolvimento no interior. Inspirada pelo processo de urbanização nacional que se iniciava, Uberlândia ${ }^{8}$ adentrou-se na passagem para a segunda metade do século XX em uma nova fase de expansão. A cidade que se tornara passagem para a capital do país reestrutura suas ruas com asfaltamento e sinalização para adequar seu caminho a condução da modernidade que se fazia cada vez mais palpável.

Além dos inúmeros eletrodomésticos e bens eletrônicos, o automóvel, produzido pela indústria fordista, a partir dos anos 50, iria promover mudanças significativas no modo de vida dos consumidores e também na habitação e nas cidades. Com a massificação do consumo dos bens modernos, especialmente os eletroeletrônicos, e também do automóvel, mudaram radicalmente o modo de vida, os valores, a cultura e o conjunto do ambiente construído. Da ocupação do solo urbano até o interior da moradia, a transformação foi profunda. (MARICATO, 2001, p. 19)

\footnotetext{
${ }^{7}$ Conforme Ignez Ferreira, "com Brasília, a ação do Estado como indutor da urbanização do país se faz de forma evidente, não só através da criação da mesma cidade e da destinação do uso de seu solo urbano, mas também pela implantação de ligações de Brasília com o interior do país e de outras medidas que, direta ou indiretamente, estimularam e permitiram a urbanização pelo interior." (FERREIRA, 1985: 44).

8 Em 1929 São Pedro de Uberabinha passou a chamar-se Uberlândia, junção de dois radicais para significar "terra fértil". A imagem de nova cidade necessitava de novo nome, que fosse mais um elemento de fortalecimento da crença em sua prosperidade e que desvinculasse a ideia de dependência da vizinha Uberaba.
}

URBANA, V.6, no 9, ago-dez, 2014 - Dossiê: Dimensões Simbólicas das Intervenções Urbanas CIEC/UNICAMP 
Conforme apresenta Beatriz Ribeiro Soares (1995), Uberlândia embrenha-se em um planejamento de expansão horizontal que ocasionou um crescimento desproporcional em relação à totalidade populacional. A ampliação do núcleo central da cidade visava à ampliação da qualidade infraestrutural e estética arquitetada nos anos anteriores, entretanto,

[...] estas transformações não atingiram a população residente nos bairros mais afastados da área central, denominados até aquele momento de vilas ou subúrbios [...] Nesses bairros persistia o problema da falta de água para abastecer a população; as ruas transformavam-se em verdadeiros lamaçais nos tempos de chuva; a iluminação pública era muito precária; os terrenos vazios viravam depósitos de lixo e entulho; o traçado urbano não obedecia a critérios técnicos, assim como a arquitetura de suas habitações (SOARES, 1995, p. 130).

Os problemas urbanos relacionados à ausência de políticas públicas efetivas mantinham-se nos bairros afastados do centro, onde se justapunham as moradias das camadas populares, sendo agravados pelo crescimento urbano. 0 processo de expulsão das moradias populares das áreas centrais significava também a manutenção e a progressão da exclusão da classe trabalhadora do acesso a serviços urbanos e condições igualitárias de vida.

A intensificação deste processo de urbanização modernizadora provocou nas cidades transformações e contradições nunca antes vivenciadas. Em Uberlândia, a criação de loteamentos nobres e do centro comercial convergiu necessariamente com o crescimento dos subúrbios. Em outras palavras, intensificar a urbanidade resultou em ampliar também a falta dela nas áreas onde não havia objetivo de abastar o projeto capitalista e os que se beneficiaram dele.

Entender que a organização do espaço urbano conecta-se diretamente às necessidades da divisão social do trabalho e da organização do modo de produção cabe considerar que, muito além da estruturação produtiva e comercial, a maximização do lucro e do controle social requer e promove a reconstrução das experiências urbanas.

Ermínia Maricato considera a segregação urbana uma das faces mais importantes da desigualdade social e parte promotora da mesma:

À dificuldade de acesso aos serviços e infraestrutura urbanos (transporte precário, saneamento deficiente, drenagem inexistente, dificuldade de abastecimento, difícil acesso aos serviços de saúde, educação e creches, maior exposição à ocorrência de enchentes e desmoronamentos etc.) somam-

URBANA, V.6, no 9, ago-dez, 2014 - Dossiê: Dimensões Simbólicas das Intervenções Urbanas CIEC/UNICAMP 
se menos oportunidades de emprego (particularmente do emprego formal), menos oportunidades de profissionalização, maior exposição à violência (marginal ou policial), discriminação racial, discriminação contra mulheres e crianças, difícil acesso à justiça oficial, difícil acesso ao lazer. A lista é interminável (MARICATO, 1996, p. 56).

A manutenção de condições precárias de vida às classe subalternizada baseia o sistema de exclusão, mantendo a grande parcela pobre da população longe dos centros a serem valorizados. Enquanto os conflitos de classe mais intensos por espaços urbanos ocorrem pela higienização social do espaço central sem dúvida, a expressão mais clara deles é a segregação destas camadas para as periferias.

Mike Davis (2006) atribui à linguagem da modernização a definição de "entraves humanos" para a população pobre que, ocupando áreas especuladas, dificultam sua valorização. Sob este aspecto, a segregação urbana

[...] não é um status quo inalterável, mas sim uma guerra social incessante na qual o Estado intervém regularmente em nome do "progresso" e do "embelezamento" e até da "justiça social para os pobres", para redesenhar as fronteiras espaciais em prol de proprietários de terrenos, investidores estrangeiros, a elite com suas casas próprias e trabalhadores de classe média (DAVIS, 2006, p. 105).

Pelo menos até a década de 1970 a área urbana uberlandense cresceu desenfreadamente, com a abertura progressiva de lotes e com clara desigualdade de infraestrutura urbana entre áreas centrais e suburbanas. Neste período é possível observar com maior clareza que a terra urbana transforma-se em produto, para incrementar o processo de crescimento e, ao mesmo tempo, de acumulação comercial na cidade.

Em 1938 a oferta de terrenos cresceu quase 50\%, uma vez que passou de 5 mil para 7,2 mil em um período em que a população quase não se altera (19.633 habitantes em 1937 e 20.114 habitantes em 1938). Seis anos mais tarde, entre 1945/46, o número de lotes lançados no mercado cresce de 8 mil para 12.193, quando a população aumenta apenas 500 habitantes. O mesmo acontece em 1953/54 quando esse número passa de 14 mil para 23.600 habitantes (SOARES, 1995, p. 133).

Os números da época permitem inferir que existiam mais terrenos que a média familiar da população, evidenciando que além de produzidos calculadamente, os terrenos estavam inseridos no arsenal do mercado. Em meados da década de 1930

URBANA, V.6, no 9, ago-dez, 2014 - Dossiê: Dimensões Simbólicas das Intervenções Urbanas CIEC/UNICAMP 
havia sido criada a empresa imobiliária uberlandense, futura Imobiliária Tubal Vilela, inaugurando oficialmente o processo especulativo institucional na cidade 9 .

A especulação imobiliária e a produção do espaço ascenderam como meio de acumulação para as elites locais. Estas elites, que se "representam como portadores da tradição local e [...] se percebem como responsáveis pela condução do município e pelo seu futuro" (DANIEL, 1988, p. 30), acabaram por conduzir a cidade segundo seus interesses por meio da dominação política, econômica, administrativa e cultural.

Entre 1950 e 1953 encontrou-se à frente da Prefeitura Municipal de Uberlândia o empresário do capital imobiliário Tubal Vilela da Silva. A imobiliária Tubal Vilela surgiu justamente deste acumulo ocorrido nas décadas de 1940 e 1950 e, conforme indica a pesquisa historiográfica de Renato Jales Silva Junior (2006), cresceu nas décadas seguintes a partir do apoio da gestão pública em conceder autorizações para investimento e extração de lucros da produção de áreas urbanas.

Ainda que a criação de novos loteamentos tenha aumentado as distâncias, aumentado a demanda e encarecido a implementação de políticas públicas, observase a inexistência de qualquer regulamentação municipal que versasse sobre a adequação da abertura de lotes às necessidades concretas da cidade. Até a década de 1980 a legislação sobre a construção civil previa normas apenas a respeito das dimensões dos loteamentos e imóveis.

Conforme constata Beatriz Ribeiro Soares (1995), a ausência ou a não aplicação de leis de uso da ocupação do solo urbano durante toda a história de Uberlândia incentivou a monopolização e a especulação da terra por parte dos proprietários, incorporadores e gestores públicos. O desenvolvimento deste mercado de investimento no capital imobiliário com conivência dos setores públicos também não foi elemento atípico, mas permeou toda a experiência de urbanização em curso nacionalmente, conforme aponta o sociólogo Lúcio Kowarick:

A ação governamental restringiu-se, tanto agora como no passado, a seguir o núcleo de ocupação criado pelo setor privado, e os investimentos públicos vieram colocar-se a serviço da dinâmica de valorização-especulação do sistema imobiliário construtor (KOWARICK, 1979, p. 31).

\footnotetext{
${ }^{9}$ Entendemos aqui por especulação institucional a produção e a valorização de imóveis realizadas por instituições que participam do circuito da acumulação capitalista através do mercado imobiliário.

URBANA, V.6, no 9, ago-dez, 2014 - Dossiê: Dimensões Simbólicas das Intervenções Urbanas CIEC/UNICAMP
} 
A estreita relação do mercado imobiliário, desde sua germinação, com o poder público da cidade reforça nossa percepção de que o parcelamento da terra urbana ocorreu predominantemente de acordo com os interesses específicos destes agentes imobiliários, sejam proprietários de terras, incorporadores e gestores públicos.

Uberlândia tornou-se uma cidade negócio para os estocadores de terrenos. É possível perceber até a década de 1980 a manutenção de intensa expansão urbana e crescimento numérico de loteamentos incompatíveis com as necessidades populacionais da época, como exemplifica Soares:

[...] entre os anos $1977 / 83$, foram abertos 49.765 lotes, elevando esse número para um total de 124.351 , para uma população urbana estimada, em 1983, de aproximadamente 273 mil habitantes. Considerando-se quatro pessoas/lote, existiam em 198355.968 terrenos desocupados na cidade para 68.383 ocupados e edificados (SOARES, 1995, p. 212).

A atividade das imobiliárias na cidade consolidou a monopolização da terra urbana pelas elites e sua transformação em objeto basilar do mercado imobiliário, ou seja, a principal mercadoria produtora de lucro por meio do empresariado imobiliário. Os movimentos de valorização, que apostaram na implantação de novos bairros na cidade, promoveram o loteamento de áreas e infraestrutura básica para habitação, tornando o mercado imobiliário o principal responsável na definição da expansão e das configurações urbanas de Uberlândia.

A experiência que se reproduziu em Uberlândia parece acompanhar o movimento geral capitalista e confirmar a observação de Lefebvre que

[...] o setor imobiliário se torna tardiamente, mas de maneira cada vez mais nítida, um setor subordinado ao grande capitalismo, ocupado por suas empresas (industriais, comerciais, bancárias), com uma rentabilidade cuidadosamente organizada sob a cobertura da organização do território. 0 processo que subordina as forças produtivas ao capitalismo se reproduz aqui, visando à subordinação do espaço que entra no mercado para o investimento dos capitais, isto é, simultaneamente o lucro e a reprodução das relações de produção capitalista (LEFEBVRE, 2001, p. 163).

Abramo (2001) afirma que o fato de o capital imobiliário dispor do solo urbano para fins diferenciados lhe confere o poder de decisão sobre o uso futuro do solo urbano. Nesse sentido, ação da imobiliária Tubal Vilela e de outras empresas especulativas criadas a partir da década de 50 por outras famílias da elite regional foi a principal promotora da expansão periférica da cidade.

URBANA, V.6, no 9, ago-dez, 2014 - Dossiê: Dimensões Simbólicas das Intervenções Urbanas CIEC/UNICAMP 
A criação de terrenos excedentes resultou em grande quantidade de terrenos vagos em todas as áreas da cidade. Os bairros criados fora do núcleo central sob este modelo de expansão produziram um espaço fragmentado e com grandes lacunas urbanas a espera de valorização. Da mesma forma, a criação de imóveis ociosos como forma da especulação e produção de lucro imediato aprofundaram o quadro de exclusão habitacional e ampliação do mercado imobiliário.

Acreditando num crescimento da cidade, em vista da instalação de novas indústrias, os proprietários resolveram armar uma verdadeira corrida aumentista nos preços dos aluguéis de casas em Uberlândia. Uma casa, que era alugada por 380 cruzeiros, até o dia 31 de dezembro, foi aumentada para 600 cruzeiros por seu proprietário ${ }^{10}$.

Sem dúvida, o crescimento promovido pelas práticas especulativas partiu de ações estratégicas no âmbito do mercado, a parte do planejamento urbano público adequado ao atendimento das demandas sociais. Isso significou a ampliação da segregação socioespacial e de grandes contingentes populacionais espoliados de direitos sociais e civis básicos. A criação de áreas e imóveis vazios, sendo monopolizadas pelas elites especuladoras, produziu maiores restrições no acesso à moradia e à infraestrutura urbanas para uma grande camada da população.

O financiamento de lotes e casas a parcelamentos embutidos de juros foi uma das táticas de mercado implementadas pelos especuladores, transformando em foco de lucratividade a comercialização de imóveis voltada para a classe trabalhadora de baixa renda (SILVA JUNIOR, 2006). Depoimentos de moradoras e moradores evidenciam as dificuldades de cumprimento dos pagamentos ao empresariado imobiliário e quitação dos imóveis.

O lote foi vendido para nós no valor de 15 mil réis, na época. Pagávamos em prestações, ou o troco de animais que o Tubal Vilela levava para a sua fazendo. Era muito caro, muita gente custou a pagar a perdeu a terra. O meu pai deixou acumular e vendemos toda a produção de alimentos e animais de trabalho para pagar juros e multas ${ }^{11}$.

${ }^{10}$ QUIRINO, Fernando. Jornal CORREIO DE UBERLÂNDIA, 15/ jan. 1973, p. 6.

${ }^{11}$ Depoimento recolhido de: SILVA, Marta Maria da. Reestruturação urbana no bairro Bom Jesus - Uberlândia. 2001. Monografia - Centro Universitário do Triângulo, Uberlândia, 2001: 45. A autora não atribui autoria ao depoimento.

URBANA, V.6, no 9, ago-dez, 2014 - Dossiê: Dimensões Simbólicas das Intervenções Urbanas CIEC/UNICAMP 
O depoimento acima, retirado da dissertação de Marta Maria da Silva (2001), soma-se a outros tantos presentes nas diversas pesquisas historiográficas que versam sobre a trajetória histórica da cidade de Uberlândia e a formação de seu tecido urbano. É possível identificar histórias e memórias de trabalhadores marcadas pelos esforços familiares para aquisição de moradia própria.

[...] aqui era mais barato, era onde ele dava conta de compra. O meu pai toda vida foi um homem assalariado, então foi aqui que ele comprou, ele teve muita dificuldade pra consegui paga e tal, então a luta foi assim com essa dificuldade toda, depois ele morreu e isso aqui ficou pros irmão. [...] Na época eu já trabaiava muito, eu já viajava, trabaiava com caminhão, consegui junta um dinheiro, falei pra muié "olha meu bem vou junta um dinheirinho porque a gente num pode vive de aluguel, aluguel é terrível, pra nós compra um terreno e fazê nossa casinha e tal". Nóis invinha trabaiano e lutano, lutano, mas nesse meio de prazo o meu pai faleceu, morreu muito novo, mau pai morreu de acidente de trabalho, então o que que aconteceu, aí Deus ajudou que eu já tava mais controlado, os irmão quis vende, eu comprei deles ${ }^{12}$.

Lúcio Kowarick (1979) afirma que o modo de produção capitalista não se organiza para prover aos trabalhadores meios de vida necessários à sobrevivência, por isso, transforma a terra urbana em mercadoria e desenvolve consequente ampliação da carência por moradia. Da mesma maneira, podemos compreender que o paradoxal desenvolvimento uberlandense caracterizou-se por atender a interesses de parcelas da classe dominante, sob a marginalização de grande parte da classe trabalhadora.

O urbanismo brasileiro (entendido aqui como planejamento e regulação urbanística) não tem comprometimento com a realidade concreta, mas com uma ordem que diz respeito a uma parte da cidade, apenas. Podemos dizer que se trata de ideias fora do lugar porque, pretensamente, a ordem se refere a todos os indivíduos, de acordo com os princípios do modernismo ou da racionalidade burguesa. Mas também podemos dizer que as ideias estão no lugar por isso mesmo: porque elas se aplicam a uma parcela da sociedade reafirmando e reproduzindo desigualdades e privilégios (MARICATO, 2001, p. 122).

12 Depoimento recolhido de: SILVA JUNIOR, Renato Jales. Cidade e Cultura: memórias e narrativas de viveres urbanos no bairro Bom Jesus Uberlândia 1960-2000. 2006. Dissertação (Mestrado em História) - Instituto de História, Universidade Federal de Uberlândia, Uberlândia, 2006, p. 49. A transcrição foi feita pelo autor em acordo com suas opções metodológicas.

URBANA, V.6, no 9, ago-dez, 2014 - Dossiê: Dimensões Simbólicas das Intervenções Urbanas CIEC/UNICAMP 
Os discursos e experiências que assentam o urbanismo reproduzido em Uberlândia fundam os conflitos e contradições que permeiam suas atuais configurações fundiárias. Tendo a urbanização industrial imposto uma extrema segregação aos grupos, etnias, estratos e classes sociais a nível global (LEFEBVRE, 2001), seu desenvolvimento produziu também cidades largamente segregacionistas. À medida que as cidades produziram as elites urbanas, oriundas das antigas elites agrárias que dominavam econômica e politicamente os espaços, produziram também a condição proletária, as experiências de trabalhadores urbanos na vivência destas cidades excludentes.

A segregação dos trabalhadores reformula os sentidos e representações atribuídos à cidade e à urbanidade. Segundo Lefebvre (2010) as cidades modernas substituem a ideia de habitar, que estaria relacionada à vivência plena do espaço urbano, por uma noção de habitat, a moradia reduzida à função de abrigar, submetida à cotidianidade alienada. Sob esta perspectiva, a racionalidade urbana fragmentadora, que intensifica as segregações de classe, para além de espoliar direitos sociais e civis estaria espoliando de grande parcela social o próprio "direito à cidade" (LEFEBVRE, 2001, p. 139).

O desenvolvimento da cidade de Uberlândia semeou a transferência para o "mercado" de grande parte da responsabilidade sob a provisão habitacional e germinou mecanismos de hierarquização de preços e de acesso à terra urbana e à moradia. O controle mercadológico da produção imobiliária significou a formação de um espaço cerceador, onde a desigualdade de renda se aprofunda ao tempo em que o acesso ao que Henri Lefebvre (2001) chamou de "às positividades do urbano" se limita a quem pode pagar.

Somente nos anos 1980 é possível identificarmos políticas públicas de planejamento urbano significativamente divergentes da lógica especulativa. Promovido pela gestão municipal Zaire Rezende (1983/88) o Imposto Predial e Territorial Urbano - IPTU progressivo, com alíquotas diferenciadas para as edificações segundo sua localização e área construída, bem como alíquota progressiva para os terrenos, tinha por objetivo frear a acumulação de terrenos vagos e incentivar a ocupação destes com moradias. A medida foi, porém, derrubada pela Câmara de Vereadores em 1991.

Também apenas nesta década ocorre um processo ordenado de descentralização comercial em Uberlândia, com surgimento de novos subcentros na malha urbana. Longe de representar a democratização de acesso à cidade, isso URBANA, V.6, no 9, ago-dez, 2014 - Dossiê: Dimensões Simbólicas das Intervenções Urbanas CIEC/UNICAMP 
ocorreu em concomitância com a intensificação da migração dos grupos de renda alta para loteamentos fechados mais afastados do centro urbano (ANDRADE, 2008). Estes loteamentos fechados consolidaram-se como marca do tecido urbano modernizado na década de 90 e podem ser vistos como a metáfora mais aperfeiçoada do isolamento proposital promovido pelas elites locais.

O desenvolvimento dos loteamentos fechados em áreas ao entorno da cidade expressaram outra característica intrínseca à segregação urbana, que não se caracteriza simplesmente pela distância social existente entre os agentes das diferentes classes sociais. Mais que distância, a segregação assentou-se em um sistema de estratificação social no espaço urbano que, independentemente de distâncias, organiza um arranjo hierárquico e uma divisão desigual do poder, da riqueza e do próprio espaço urbano entre classes que compartilham o espaço (CASTELLS, 1975).

As normatizações empenhadas pelo poder público local em meados da década de 80 não tiveram êxito em minimizar os efeitos da especulação imobiliária e menos ainda a concentração fundiária na cidade sofreu diminuições significativas. A lógica segregacionista e espoliativa que produziu a limitação do acesso à moradia e à infraestrutura urbanas a classe trabalhadora permaneceu como marca consolidada no desenvolvimento uberlandense.

Entre as décadas de 70 e 80 foram abertos 62.534 lotes. Em 1970, constatase $64,5 \%$ da área urbana loteada sem ocupação. Em 1980, em função do crescimento populacional o número diminuiu para $48,1 \%$ de áreas em situação de vagas. Em 1984, novamente esta porcentagem cresce para 53,9\% e em 1991 as áreas ociosas já chegavam a 63,7\% de toda a área urbana (BESSA; SOARES, 1997).

Os dados que mostram a grande fragmentação do espaço cruzam-se com os Mapas do Plano Diretor de Uberlândia utilizados por Beatriz Ribeiro Soares (1995) e que apontam que em 1994 a maior parte das áreas da cidade, contando quase a totalidade das áreas periféricas, foi produto do monopólio de agentes especuladores, reforçando a percepção de que Uberlândia encerrou o século XX em domínio da lógica da expansão periférica promovida pelo mercado imobiliário.

URBANA, V.6, no 9, ago-dez, 2014 - Dossiê: Dimensões Simbólicas das Intervenções Urbanas CIEC/UNICAMP 


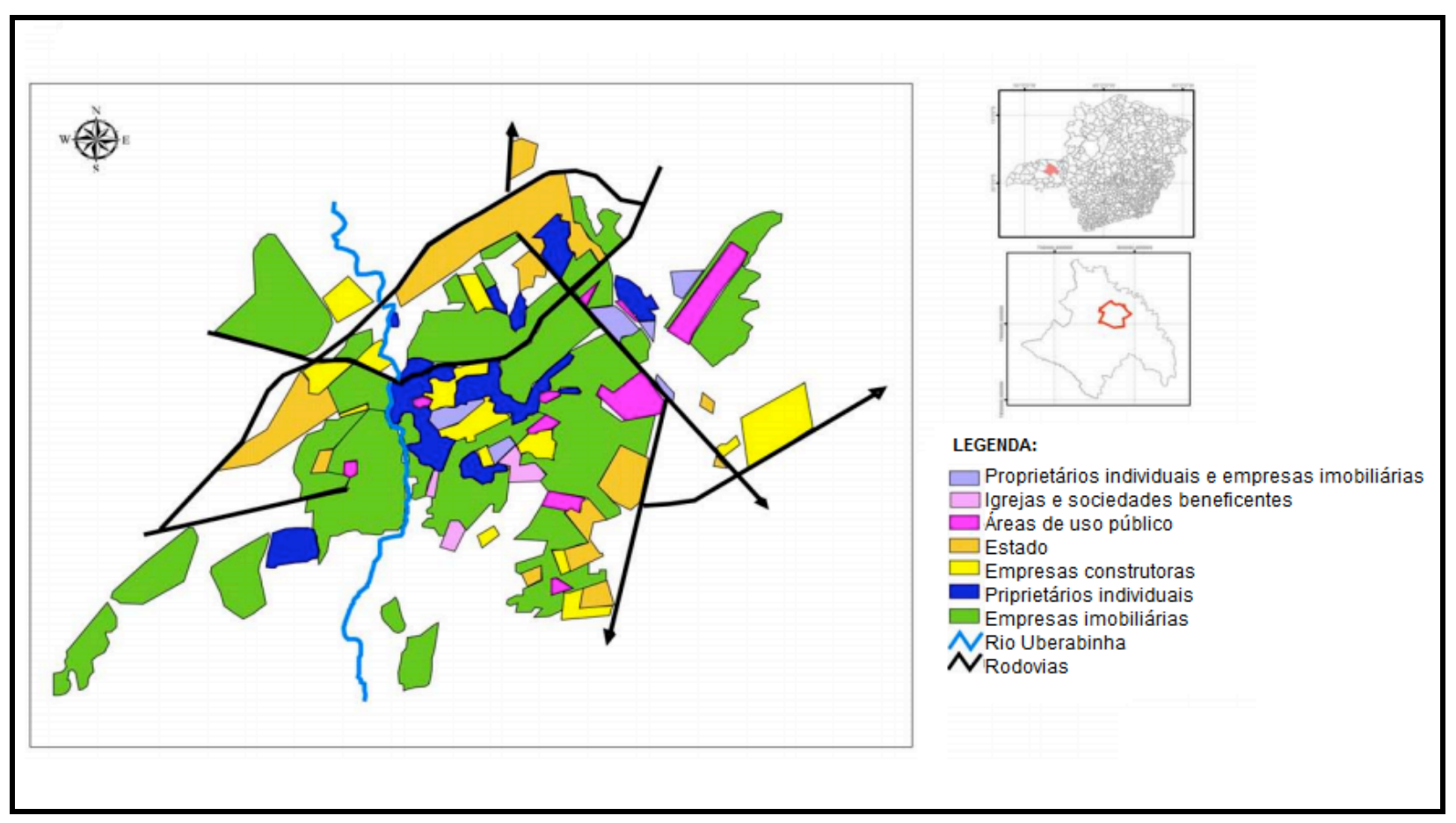

Figura 2 - Agentes que Produziram o Espaço Urbano de Uberlândia (1994)

Fonte: Soares (1995)

Frente a esta realidade, a construção de loteamentos populares financiados pelo poder público aos trabalhadores de baixa renda se firmou na década de 90 como elemento fundamental no jogo especulativo e na consequente ampliação de periferias carentes de estruturação urbana adequada. Segundo dados do Centro de Pesquisa Socioeconômica - CEPES da Universidade Federal de Uberlândia no mesmo ano de 1994 45\% dos moradores de 27 bairros periféricos de Uberlândia viviam em miséria absoluta, isto é, abaixo da linha de pobreza, definida como a condição de se adquirir alimentação básica (SOARES, 1995).

Neste sentido, Rykwert discute que a realidade final do século $X X$

[...] opõe a cidade "projetada" - em que a primeira consideração é a forma urbana e a existência de algum diálogo com os habitantes - à cidade muito mais difusa e insidiosa das redes "organizadas" pelos engenheiros sanitaristas e de tráfego cujos interstícios são preenchidos pelos construtores e especuladores: a cidade da eficiência conduzindo ao lucro (RYKWERT, 2004, p. 330).

A antiga São Pedro de Uberabinha, que havia conduzido seu desenvolvimento e urbanização nos trilhos da Mogiana e continuamente nas vias rodoviárias se desenvolveu adequando-se ao atendimento do movimento de acumulação do capital no país. A Uberlândia moderna que se consolidou como centro regional econômico e URBANA, V.6, no 9, ago-dez, 2014 - Dossiê: Dimensões Simbólicas das Intervenções Urbanas CIEC/UNICAMP 
cultural nas últimas décadas do século $X X$ manteve seu desenvolvimento econômico aliado à monopolização da posse da terra urbana por uma elite minoritária.

O último diagnóstico estratégico de habitação de interesse social ocorreu no ano de 2009. O documento fez parte do Plano Local de Habitação de Interesse Social de Uberlândia (PLHIS), construído pela articulação da Prefeitura Municipal de Uberlândia, com o Ministério das Cidades e a Caixa Econômica Federal, e apresenta alguns indicadores sobre a situação social e habitacional da cidade no ano de 2009.

O PLHIS (2009) é composto por levantamentos e análises de dados e informações técnicas sobre diversos aspectos da cidade, reproduzindo a exaltação de aspectos econômicos da cidade, como sua posição estratégica de entreposto comercial, sua liderança em desenvolvimento no Triângulo Mineiro, e sua posição entre as 10 cidades brasileiras mais viáveis para novos investimentos empresariais. É possível perceber em todo o corpo redacional do PLHIS (2009) a manifestação ufânica sobre o desenvolvimento econômico da cidade, naturalizando sua "vocação" para as atividades comerciais, para o progresso e para o destaque.

Uberlândia pode ser chamada centro de progresso: conceito que se justifica plenamente nestes 121 anos de vida. Conjugando, a um só tempo, desenvolvimento e qualidade de vida e, fortalecida na sua identidade futurista, assume o papel de município cada vez mais de acordo com a modernidade e as constantes transformações exigidas pelo mundo globalizado (UBERLÂNDIA, 2009a, p. 21).

Não obstante, a estimativa de renda considerou que em $200940 \%$ da população obtinha renda de até 3 salários mínimos, totalizando 253.738 pessoas, e que $36 \%$ da população estava incluída no seguimento sem rendimentos, 228.364 pessoas. Em contraste, $2 \%$ da população detinha renda mensal maior que o valor de 20 salários mínimos (UBERLÂNDIA, 2009a). Estes números evidenciam a significativa concentração de renda que acompanhou esta condição de desenvolvimento.

O resultado final do diagnóstico estratégico de habitação de interesse social do PLHIS (2009) afirma logo no início que "Uberlândia é uma cidade com toda a infraestrutura necessária para suprir as necessidades de seus habitantes" (UBERLÂNDIA, 2009a: 17), evidenciando a negligencia do próprio plano, e do poder público administrativo, em reconhecer a habitação (e seu déficit) como parte da infraestrutura urbana.

O diagnóstico apresenta que no então ano, em que a área total do município era de $4.115,822 \mathrm{~km}^{2}$ com $219,00 \mathrm{Km}^{2}$ de área urbana, a cidades é localizada entre URBANA, V.6, no 9, ago-dez, 2014 - Dossiê: Dimensões Simbólicas das Intervenções Urbanas CIEC/UNICAMP 
as cidades de mesmo porte com maiores padrões de desigualdade, e alto déficit habitacional absoluto. Situa-se, assim, a nível nacional entre os municípios que mais concentram déficit habitacional, os "poucos municípios (575), que concentram 46\% do déficit habitacional total" (UBERLÂNDIA, 2009a, p. 57).

Também no PLHIS (2009) são identificados em 200916 assentamentos precários classificados nas categorias favela e loteamento irregular, situados na área urbana, estando 09 em terrenos de propriedade particular, 05 em área de titularidade pública e 02 ocupações em que não se tem identificado o título de propriedade. Estas habitações correspondiam a 15.962 pessoas vivendo em situações precárias de moradia e sobrevivência, conforme mostram os dados da TABELA 1:

Tabela 1 - Dados dos Assentamentos Precários em Uberlândia (2009)

Fonte: UBERLÂNDIA (2009a)

\begin{tabular}{ccccccc}
\hline Tipologia & $\begin{array}{c}\text { No } \\
\text { assentamentos }\end{array}$ & $\%$ & Domicílios & $\%$ & População & $\%$ \\
\hline Favela & 6 & 37,50 & 826 & 19,02 & 3.035 & 19,01 \\
$\begin{array}{c}\text { Loteamentos } \\
\text { irregulares }\end{array}$ & 10 & 62,50 & 3.516 & 80,98 & 12.927 & 80,99 \\
\hline Total & $\mathbf{1 6}$ & $\mathbf{1 0 0}$ & $\mathbf{4 . 3 4 2}$ & $\mathbf{1 0 0}$ & $\mathbf{1 5 . 9 6 2}$ & $\mathbf{1 0 0}$ \\
\hline
\end{tabular}

A Estimativa dos Componentes do Déficit Habitacional Básico da cidade apresentados pelo diagnóstico soma ao mapeamento de moradias precárias, conforme TABELA 2, mais 36.178 habitações em déficit na cidade, apontando outras formas de moradia precarizantes vivenciadas pela população trabalhadora.

Tabela 2 - Componentes do Déficit Habitacional Básico de Uberlândia (2009)

Fonte: UBERLÂNDIA (2009a)

\begin{tabular}{ccc}
\hline Componentes do Déficit & Déficit & $\%$ \\
\hline Domicílios improvisados & 904 & 2,50 \\
Famílias conviventes & 13.994 & 38,68 \\
Cômodos & 1.469 & 4,06 \\
Domicílios rústicos & 879 & 2,43 \\
\hline
\end{tabular}

URBANA, V.6, no 9, ago-dez, 2014 - Dossiê: Dimensões Simbólicas das Intervenções Urbanas CIEC/UNICAMP 
Domicílios alugados por famílias com renda de

até 3 S.M.

Posto este e outros dados, temos que o déficit habitacional da cidade é apresentado pelo PLHIS (2009) da seguinte forma:

[...] considerando o Índice Habitacional Brasil (IH) medido pela Fundação João Pinheiro que é de 3,47 habitantes por domicílio e a população total de Uberlândia de 634.345 habitantes, teremos na divisão do segundo pelo primeiro um número ideal para Uberlândia de 182.808 unidades habitacional de domicílios adequados. A diferença entre a quantidade de domicílios adequados, com a quantidade de domicílios ideal deve ser considerada o déficit habitacional, ou seja, 49.552 unidades habitacionais (UBERLÂNDIA, 2009a, p. 113, grifos nossos).

O cenário social e habitacional da cidade no ano de 2009 explicita que os planos urbanos encampados pelas elites dirigentes, detentoras do controle dos principais aparelhos institucionais desde a formação da cidade, nunca contemplaram a solução de seus problemas sociais, como a grande desigualdade de renda, o déficit habitacional e o próprio cerceamento dos trabalhadores ao direito à cidade. Muito pelo contrário, a desigualdade social marcante na cidade foi tida como mais uma peça no jogo mercadológico, sustentando táticas do empresariado com vistas a aprofundar cada vez mais os lucros e a própria exclusão social, lógica muito bem explicada por Milton Santos:

Havendo especulação, há criação mercantil da escassez e o problema do acesso à terra e à habitação se acentua. Mas o déficit de residências também leva à especulação e os dois juntos conduzem à periferização da população mais pobre, e, de novo, ao aumento do tamanho urbano. As carências em serviços alimentam a especulação, pela valorização diferencial das diversas frações do território urbano. A organização dos transportes obedece a essa lógica e torna ainda mais pobres os que devem viver longe dos centros, não apenas porque devem pagar caro seus deslocamentos como porque os serviços e bens são mais dispendiosos nas periferias. E isso fortalece os centro em detrimento das periferias, num verdadeiro círculo vicioso. (SANTOS, 1993, p. 96)

Nas últimas décadas a população de Uberlândia vivenciou a continuidade deste ciclo, experimentando no espaço urbano a materialização das estruturas de poder e dominação social que se sustentaram historicamente no discurso desenvolvimentista URBANA, V.6, no 9, ago-dez, 2014 - Dossiê: Dimensões Simbólicas das Intervenções Urbanas CIEC/UNICAMP 
dos dirigentes administrativos e econômicos. A cidade consubstanciou-se, assim, nas experiências históricas, sociais e cotidianas não apenas como "um mero cenário para as relações sociais, mas uma instância ativa para a dominação econômica e ideológica" (MARICATO, 1996, p. 168).

Estas conjunções foram construídas, ao longo da história da cidade, sob um ideário pautado na ordem e no progresso de uma cidade predestinada à prosperidade. Para tanto, a associação desta prosperidade com a disciplina e a cooperação de seus trabalhadores foi fundamental no discurso dos produtores do progresso.

Ocorre que a realidade vivenciada, gerada pela produção capitalista do espaço e caracterizada pela precariedade de condições de vida urbana, fez do espaço urbano excludente instância também própria de um "conflito permanente entre a cidade promessa e a cidade vivenciada pelos trabalhadores" (MEDEIROS, 2002, p. 34).

"A tensão existente entre a cidade formal e a cidade ilegal é dissimulada". A frase de Maricato (2000, p. 165) evidencia a lógica histórica e dialética sob a qual se mantém em movimento a produção da cidade. A cidade é, em outras palavras, ao mesmo tempo produto e cenário histórico da produção e reprodução das relações sociais, constituindo-se a partir dos mais variados processos de disputa social entre as classes antagônicas.

É nesse sentido que compreendemos a edificação da cidade de Uberlândia como representação concreta e simbólica de um projeto de cidade excludente, que delimita espacialmente a segregação social sob a qual é projetada e fundada. Entendemos que a exclusão ou a precariedade do acesso a serviços e equipamento urbanos para os trabalhadores é parte indissociável do projeto político de desenvolvimento e urbanidade formulado e mantido em vigor pela classe dominante.

O déficit habitacional, em seu sentido mais amplo quanto à totalidade de equipamentos e serviços urbanos necessário ao abrigo e a subsistência familiar, apresenta-se, assim, como efeito direto da imperatividade do mercado imobiliário na produção e organização do espaço urbano. Milhares de famílias sem renda suficiente para incorporar-se no consumo do mercado formal são resultados da objetividade desta realidade.

\section{Referências}

ABRAMO, Pedro (2001). Mercado e ordem urbana: Do caos à teoria da localização residencial. Rio de Janeiro: Bertrand Brasil.

URBANA, V.6, no 9, ago-dez, 2014 - Dossiê: Dimensões Simbólicas das Intervenções Urbanas CIEC/UNICAMP 
ANDRADE, Lívia Maria de. Cidade da dança. 2008. Trabalho Final de Graduação (Arquitetura e Urbanismo). Universidade Federal de Uberlândia, Uberlândia, 2008.

BESSA, Kelly Cristine; SOARES, Beatriz Ribeiro (Jan./Dez. 1997). O Significado da Especulação Imobiliária no Espaço Urbano de Uberlândia - MG. Revista história e perspectiva. Uberlândia, no 16/17, p. 121-148.

BOSI, Antônio de Pádua (2004). Reforma Urbana e Luta de Classes. Uberabinha/MG (1888 a 1922). São Paulo: Xamã.

CASTELLS, Manuel (1975). A questão urbana, São Paulo: Paz e Terra.

DANTAS, Sandra Mara (2001). Veredas do progresso em tons altissonantes Uberlândia (1900-1950). 2001. Dissertação (Mestrado em História) - Instituto de História, Universidade Federal de Uberlândia.

DANIEL, Celso (1988). Poder local no Brasil urbano. In: Espaço e Debates, Ano VII, no 24.

FERREIRA, Ignez (1985). O processo de urbanização e a produção do espaço metropolitano de Brasília. In PAVIANI, Aldo (org). Brasília, ideologia e realidade: o espaço urbano em questão. São Paulo: Projeto.

GUIMARÃES, Eduardo Nunes (2010). Formação e Desenvolvimento Econômico do

Triângulo Mineiro: integração nacional e Consolidação regional. Uberlândia: EDUFU.

KOWARICK, Lúcio (1979). A espoliação urbana. Rio de Janeiro: Paz e Terra.

LEFEBVRE, Henri (2001). O direito à cidade. São Paulo: Centauro.

LOURENÇO, Luís Augusto Bustamante (2010). O Triângulo Mineiro, do Império à

República: o extremo oeste de Minas Gerais na transição para a ordem capitalista (segunda metade do século XIX). Uberlândia: Edufu.

LOPES, Valéria Maria Queiroz Cavalcanti (2008). Novos trilhos, outras trilhas. In: BRITO, Diogo de Souza, WARPECHOWSKI, Eduardo Morais (org.) Uberlândia revisitada memória, cultura e sociedade. Uberlândia: Edufu.

MACHADO, Maria Clara Tomaz (1990). A Disciplinarização da Pobreza no Espaço Urbano Burguês: assistência Social Institucionalizada - (Uberlândia - 1965 a 1980). 1990. Dissertação (Mestrado em História). São Paulo: Universidade de São Paulo.

MARICATO, Ermínia (1997). Brasil 2000: qual planejamento urbano? Cadernos IPPUR, Rio de Janeiro, Ano XI, n. 1 e 2, p. 113-130.

(2000). As idéias fora do lugar e o lugar fora das idéias. In ARANTES, O.;

MARICATO, E.; VAINER, C. A cidade do pensamento único. Desmanchando consensos. Petrópolis: Editora Vozes.

URBANA, V.6, no 9, ago-dez, 2014 - Dossiê: Dimensões Simbólicas das Intervenções Urbanas CIEC/UNICAMP 
MEDEIROS, Euclides Antunes de (2002). Trabalhadores e viveres: trajetórias e disputas na conformação da cidade Uberlândia- 1970/2001. 2002. Dissertação (Mestrado) - Instituto de História, Universidade Federal de Uberlândia, Uberlândia.

PRADO JÚNIOR, Caio (1990). História Econômica do Brasil. São Paulo: Brasiliense. RELPH, Edward (1990). A paisagem urbana moderna. Lisboa: Edições 70.

RYKWERT, J (2004). A sedução do lugar. A história e o futuro da cidade. São Paulo: Martins Fontes.

SADER, Eder (1995). Quando novos personagens entram em cena. 30 ed., Rio de Janeiro: Paz e Terra.

SANTOS, Milton (1993). A urbanização brasileira. São Paulo: Hucitec.

SILVA JUNIOR, Renato Jales (2006). Cidade e Cultura: memórias e narrativas de viveres urbanos no bairro Bom Jesus Uberlândia 1960-2000. 2006. Dissertação (Mestrado em História) - Instituto de História, Universidade Federal de Uberlândia, Uberlândia.

SILVA, Marta Maria da (2001). Reestruturação urbana no bairro Bom Jesus Uberlândia. 2001. Monografia - Centro Universitário do Triângulo, Uberlândia.

SOARES, Beatriz Ribeiro (1988). Habitação e Produção do Espaço em Uberlândia. Dissertação (Mestrado). 290 f. Departamento de Geografia da Faculdade de Filosofia, Letras e Ciências Humanas da Universidade de São Paulo. Universidade de São Paulo, São Paulo.

(1995). Uberlândia: da Cidade Jardim ao Portal do Cerrado - imagens e representações no Triângulo Mineiro. 1995. Tese (Doutorado) Departamento de Geografia da Faculdade de Filosofia, Letras e Ciências Humanas da Universidade de São Paulo, São Paulo.

UBERLÂNDIA (2009a). Secretaria Municipal de Habitação. Plano local de habitação de interesse social: diagnóstico estratégico de habitação de interesse social. Uberlândia.

(2009b). Secretaria Municipal de Habitação. Plano local de habitação de interesse social: metodologia para desenvolvimento do plano local de habitação de interesse social do município de Uberlândia. Uberlândia.

URBANA, V.6, no 9, ago-dez, 2014 - Dossiê: Dimensões Simbólicas das Intervenções Urbanas CIEC/UNICAMP 